\section{SCIENTIFIC INSTRUCTION AT THE IOWA STATE UNIVERSITY}

THE American Scientific Monthly states that the faculty of the State University of Iowa have, with marked unanimity, resolved to recommend to the Board of Regents a new course of study for the first three years, in order to adapt the internal organisation of the institution to the spirit of the new organic law passed by the late General Assembly.

According to this plan, the students have four regular hours of work, lecture, or recitation each school day. This time is equally divided between the letters (language, history, \&c.), and the sciences (mathematics, physical and natural science). The direction of these two classes of studies is to be respectively under the Faculty of Letters and the Faculty of Science, each to have complete control over one-half of the students' time.

Of the two hours spent in the different sciences, one hour is devoted to mathematics, the other, in the two first years to physical, in the third year to natural science. This order might, perhaps, with advantage to the student, be changed so as to have the second year in physical science succeed instead of precede the year in natural science; the student would thereby profit from his greater proficiency in mathematics.

After having completed this three-years' course-which is the same for all students in the sciences, but permits the student, under certain wholesome restrictions, to substitute the different languages one for the other-the student can intelligently decide whether he desires to graduate in the sciences, the letters, or in pedagogics. In the last case, he needs not to have studied any foreign language, but will have spent a great amount of time in the study of his vernacular and its literature; he may then enter the Normal Department, and, at the close of one year, receive the degree of B.D. (Bachelor of Didactics). If, however, he has studied foreign languages, especially Latin and German, he can, after two years of studies, selected according to his own pleasure from among the higher branches taught at the University, obtain either the degree of B.Ph. (Bachelor of Philosophy) or B.A. (Bachelor of Arts). To obtain the former, at least two-thirds of the studies selected by him must have been in the department of Science, while to obtain the latter degree the same fraction should have been studied in the department of Letters.

Facilities for part-graduate courses are also offered, and have, indeed, already been improved by several gentlemen in the past year. We abstain from giving forth details concerning this plan until the Board of Regents shall have taken action thereon. We believe, however, that this plan, in a judicious manner, combines the best features of the American College system with the German University system. It will equally prevent one-sidedness and class-drudgery; while securing familiarity with the elements of the principal branches of human culture, it will, at the same time, not only permit each mind to follow its own bend, but also give every individual a fair chance to ascertain correctly in what direction his mind leads him.

This new organisation is especially important to those interested in science. Hitherto, most students commenced the study of science after having spent several years in book studies, especially the dead languages. It seemed they had been imbued with the abstird notion that such studies form a proper preparation for the study of physical and natural science. Expcrience has, however, abundantly confirmed the common-sense view, that the exclusive pursuit of such litcrary bianches, by permitting the faculties of obscrvation and logical reasoning to slumber, does unfit students for the successful study of nature. For the sake of the siulent, we are glad that this system, at last, has been thorough'y abandoned. The students will hereafter commence the study of physical science immediately upon entering the University, and, in regular succession, become familiar with the elements and principles of the same. They will take up the natural sciences only after they have become familiar with the elements of physical science. Hereby the professors of physical and natural sciences will, at last, have an opportunity given to teach science in such a manner and at such a time as they deem necessary. We are glad to state that this great reform has the cordial support of each member of the facuity.

\section{NEW CLASSIFICATION OF CLOUDS*}

$\mathrm{NO}$ one is ignorant that the study of clouds is, from the point of view of our practical needs, one of the most important questions meteorology can present us. Indeed, there is no other meteorological manifestation can so fix the attention of the yeoman in the city, of the agriculturist in the country, of the tourist on the mountain's summit, of the soldier in war, of the sailor in continual strife with the disturbances of atmosphere and sea, and, in fine, of the savant in general.

We everywhere see these different social elements continually watching the diverse appearances which the clouds offer us, and casting upon them a look of interrogation, of disquietude, of desire, of a wish constantly renewed to grasp their forms, in order to predict good or bad weather, according to our social needs.

It is especially when the atmosphere threatens some perturbation, rain, storm, tempest, that the common people examine the character of the clouds. But how often; at every moment of the day, do they ask each other about the temperature, hot, cold, or wet, which sensibly exists, while just as often do they pass by unheedingly the clouds, which exert a no less direct or indirect action upon atmospheric variations, as well in the abnormal state as in the normal.

Moreover each country, according to its geographical position, topography, \&c., has its own type of clonds. Here the Cirruts predominates, there the Cumulus, elsewhere such and such form of clouds which do not exist in other places. All these different appearances of clouds are everywhere intimately connected with some particular condition of climate, and these climatological conditions powerfully influence, in their turn, the health, agriculture, navigation, and the thousand other social concerns of humanity. We may say that the clouds are a great book of nature, constantly open for the perusal of all classes of society. Like a compass, the clouds show us at every instant the direction, the velocity, and the altitude of the superior currents which afterward determine the inferior winds at the surface of the earth. There is, therefore, a permanent weathercock as long as the sky contains a single cloud, however small it may be.

There is necessity, therefore, for undertaking a profound study of cluuds in their diverse scientific and social applications; for making researches upon the nature, form, quantity, cirection, velocity, and azimuthal rotation of clouds, corresponding to each stratum perfectly characterised by the origin, intimate constitution, and meteoric products of the vesicular vapours and congealed particles which constitute them. For, in the intimate nature of clouds there is a fundamental condition to be estab. lished, which results from the physical force acting immediately after gravitation, upon their constitution. This is the element of heat.

Despite this scientific interest, despite this practical need which each feels, and which is so universally acknowledged, despite all this, the study of clouds is yet unhappily in its infancy. It is rarely one sees "clouds" inscribed in the meteorological registers of observatories, and when they are, the registrar has wholly neglected to note their form, their quantity, their direction, their velocity, and their azimuthal rotation. Some say simply, "clouds ;" others mention the form or the quantity, may be the direction, or exceptionally these three elements, but assuredly they neglect the velocity, and especially the azimuthal rotation which I have first signalised in clouds, and which is not yet understood. In fine, not a single register gives these five elements for one stratum of cloud, much less for each distinct stratum of those which very often appear superposed in the atmosphere.

* Contributed by Prof. Poes, of Havana, to the Semi-Annual Session of the National Academy of Sciences, held at Washington, 